БОЛЬШАКОВА Юлия Михайловна - кандидат политических наук, старший научный сотрудник Института политической психологии и прикладных политических исследований Ленинградского государственного университета им. А.С. Пушкина (196605, Россия, г. Санкт-Петербург, Пушкин, Петербургское ш., 10; academy.prof.com@gmail.com)

\title{
КОНЦЕПТУАЛИЗАЦИЯ ПУБЛИЧНЫХ УСЛУГ И ПУБЛИЧНОЕ УПРАВЛЕНИЕ
}

\begin{abstract}
Аннотация. В работе предпринята попытка концептуализации публичных услуг в контексте публичного управления. Автор показывает, что публичная услуга имманентно связана с публичным управлением, и трудности ее концептуализации естественным образом связаны с кризисом современного публичного управления на фоне возросшей динамики усложнения общества. Преодоление трудностей концептуализации публичных услуг увязывается с отказом от позитивистских подходов и обращением к диалектическим.
\end{abstract}

Ключевые слова: публичная услуга, концептуализация, публичное управление, публичное благо, кризис публичного управления

\begin{abstract}
$\mathrm{A}$ ктуализация понятия «публичная услуга» началась в конце индустриальной эпохи, когда товарное производство стало заметно уступать производству благ другого вида - услуг. После того, как экспансия производства услуг коснулась публичной сферы, публичная услуга в рамках нового государственного менеджмента обрела роль основного формата публичного управления. Вместе с тем по мере расширения использования этого термина стала проявляться и отрицательная тенденция - появление многообразных контекстуальных интерпретаций, результатом которого стала утрата определенности смыслового значения этого понятия (термина), повлекшая, в свою очередь, трудности в практическом использовании.

Эта проблема нашла особо острое выражение на уровне международных интеграционных объединений, например Европейского союза. Так, М. Манжено отмечает, что терминологические различия, семантическая путаница и разные традиции государств-членов привели ко многим недоразумениям при обсуждении на европейском уровне. В контексте услуг, представляющих общий интерес, используются различные термины и определения, различные исторические, экономические, культурные и политические явления. Терминология сообщества пытается учесть эти различия: «даже если настоящей европейской доктрины еще не существует, общий язык развивается, и общее видение постепенно появляется» [Public Administrations... 2005: 4]. Отметим, что такого рода дискуссии и обсуждения начались еще с 1957 г. (Римский договор), были продолжены в «Зеленой книге» 2003 г. и «Белой книге» 2003 и 2004 гг. Европейской комиссии и остаются актуальными и в настоящее время.

Соглашаясь с общей оценкой ситуации, данной М. Манжено, мы вместе с тем не можем разделить его оптимизм, касающийся перспектив скорой концептуализации понятия «публичные услуги». И тот факт, что за прошедшее с момента публикации его работы время ситуация мало изменилась, говорит о том, что наши опасения не беспочвенны. Представляется, что причины сложившегося положения носят фундаментальный характер эпистемологической природы. Обоснование этого тезиса и преодоление вытекающих отсюда методологических трудностей и составляет цель настоящей статьи. Для достижения этой цели необходимо последовательно решить следующие задачи:

- сформулировать полную систему сущностных признаков публичной услуги;
\end{abstract}


- концептуализировать публичную услугу через понимание ее как акта публичного управления;

- увязать трудности концептуализации публичной услуги с кризисом публичного управления;

- показать эпистемологическую природу трудностей проблемы концептуализации публичных услуг.

Формирование системы сущностных (содержательных) признаков мы начнем с постулирования публичной услуги как публичного блага. Отдавая себе отчет в противоречивости понятия блага (к этому вопросу мы еще вернемся), отметим, что в нормативном плане это положение представляется достаточно очевидным. Далее, вслед за А. Рубинштейном, определим публичное благо через такие его свойства, как неисключаемость и неконкурентность в потреблении [Карловская 2009: 137]. Наконец, мы должны сопоставить уже найденные признаки публичного блага со смысловыми значениями понятия «публичный» в широком смысле слова, чтобы не упустить какие-либо еще существенные признаки. Таких значений, согласно толковому словарю Д. Ушакова, два: 1) совершающийся в присутствии общества, публики, открытый, гласный и 2) общественный, находящийся в распоряжении общества, устроенный для общества 1 . Если второе значение перекрывается свойствами публичного блага, то первое значение явным образом в них не входит, и мы должны добавить его в качестве еще одного существенного признака публичной услуги. Таким образом, в промежуточном варианте публичную услугу можно определить как благо, обладающее свойствами неисключительности и неконкурентности в потреблении и открытым образом производимое и потребляемое.

Системный характер отраженных в этой формуле сущностных признаков публичной услуги выражается в том, что элиминирование хотя бы одного из них делает немыслимым и саму публичную услугу как явление. Покажем, как с помощью этой системы сущностных признаков могут разрешаться противоречия в толковании публичной услуги.

Один из наиболее типичных и часто встречающихся примеров такого рода противоречий связан с существованием двух альтернативных точек зрения на то, является ли государство монополистом в производстве публичных услуг, или же они могут производиться в негосударственном секторе.

Так, П. Спикер указывает, что публичные услуги - не то же самое, что государственный сектор, несмотря на подобную их идентификацию в ряде работ: «государственный сектор принадлежит или, по крайней мере, контролируется государством; публичные услуги могут им и не контролироваться» [Spicker 2009].

Некоторые публичные услуги создаются, разрабатываются и управляются независимыми, добровольными и некоммерческими организациями. Они включают в себя, например:

- независимые библиотеки: «они предоставляют публичные услуги»2;

- общественное вещание: «мы полностью привержены обеспечению общественного обслуживания без государственного финансирования» ${ }^{3}$;

- добровольные аварийные службы: «организации, которые, по сути, оказывают публичные услуги при реагировании на чрезвычайные обстоятельства...

\footnotetext{
1 Ушаков Д.Н. 1940. Толковый словарь. Доступ: https://dic.academic.ru/dic.nsf/ushakov/991006 (проверено 04.11.2019).

2 Southern Education Library Board. 2006. URL: http://www.selb.org/news/news2006/survey/survey.htm (accessed 11.07.2019).

3 Irish Independent 2009. URL: http://www.abadss.com/forum/91-fta-newsannouncements/34767-wefully-committed-providing-public-service-without-irishindepende.html (accessed 02.06.2019).
} 
например, Королевский национальный институт спасательных шлюпок, который не является частью государственного сектора, но, как мы все понимаем, эффективно выполняет общественную роль и общественный долг» ${ }^{1}$

Другими примерами могут быть университеты, которые в некоторых странах находятся в государственном ведении, другие являются независимыми некоммерческими организациями [Bolderson, Mabbett et al. 1997].

Если проанализировать систему содержательных признаков, то видно, что данное противоречие разрешается в пользу государства, поскольку только оно обладает необходимыми ресурсами для реализации всех этих признаков, в то время как негосударственные организации в силу ограниченности ресурсов не в состоянии обеспечить такое свойство публичной услуги, как неконкурентность в потреблении, при том, что остальные признаки (например, открытость, полезность и др.) могут реализовываться.

В других случаях несостоятельность негосударственных организаций в производстве публичных услуг выражается в их неспособности реализовать такие признаки, как открытость или полезность (благость).

Если государство всегда вносит определенную нормативность [Spicker 2009] в производство публичных услуг, гарантирующую их полезность, то, например, в случае несанкционированного производства средств самообороны и торговли ими, которые осуществлются частными организациями, не говоря уже о подпольном изготовлении и продаже алкогольной продукции, речь о таких гарантиях идти не может.

Итак, мы приходим к выводу, что государство действительно является монополистом в производстве публичных услуг. При этом возникает другой уровень противоречий, препятствующий их концептуализации. Эти противоречия возникают в связи с вопросом, все ли услуги, производимые государством, являются публичными? И если являются, то при каких условиях?

Поясним это на следующих примерах.

Так, П. Спикер задается вопросом, являются ли публичной услугой «действия, которые ничего не дают непосредственно общественности, такие как, например, охрана заповедников, которые защищают виды животных, а не людей. Можно утверждать, что они обеспечивают некоторую общественную выгоду, но при этом не являются публичной услугой» [Spicker 2009].

Другим примером из этой серии противоречий является государственная поддержка промышленности или сельского хозяйства, которая в одних случаях не рассматривается как публичная услуга, а в других, как, например, страхование урожая в некоторых странах Южной Европы, является формой социального обеспечения [Spicker 2009].

Сюда же можно отнести и рассуждения такого рода: «публичные услуги, как правило, должны улучшать общественное благосостояние, это может означать, что такая деятельность, как защита безопасности, является публичной услугой, когда она увеличивает благосостояние, и не является таковой, когда она ее уменьшает» [Spicker 2009].

Характер приведенных противоречий не позволяет их разрешить в рамках сформулированной нами системы содержательных признаков, сохраняющей свою статичность, поскольку здесь свойство полезности каждой услуги, производимой государством, оценивается либо с тактической, либо со стратегической точки зрения, т.е. с позиции формальной логики. Разрешение этого противоречия возможно, если оценивать полезность производимой государством

\footnotetext{
${ }^{1}$ Hansard. 2007. 5th February Column 568. URL: http://www.publications.parliament.uk/pa/ld200607/ ldhansrd/text/70205-0014.htm (accessed 04.11.2019).
} 
услуги как результат выполнения им производительной, распределительной и контролирующей функции - иными словами, в контексте публичного управления. Это означает в числе прочего, что производимая нами концептуализация на основе содержательных признаков в названном контексте приобретает дополнительно процессный, временно́й, а стало быть диалектический характер. Соответственно, в новой концептуальной версии публичную услугу следует определить как акт публичного управления.

Несмотря на приведенные примеры успешного разрешения противоречий в рамках этой концептуальной версии публичных услуг, необходимо отметить, что это оказалось возможным в тех случаях, когда услуга имела в достаточной мере утилитарный характер и допускала оценку на основе рационально-экономических представлений. Уместно в этой связи напомнить, что публичное управление в формате публичной услуги получило распространение именно в рамках нового государственного менеджмента, для которого как раз и были характерны такого рода основания для оценки. Рационально-экономическая аргументация оказалась явно недостаточной для реализации таких признаков публичной услуги, как полезность (ценность, благость) или открытость, когда они приобретали более абстрактный характер и порождали противоречия между индивидуальными и коллективными интересами. Как указывает в этой связи П. Спикер, «хорошо знакомо утверждение о том, что невозможно вывести социальные интересы просто из суммы индивидуальных предпочтений и наоборот. Гораздо реже можно увидеть следствие: в некоторых случаях индивидуальные интересы могут быть предпочтительней, а в других случаях могут быть предпочтительнее социальные» [Spicker 2009]. Эту ситуацию он хорошо иллюстрирует примером Джейми Боуэн: «...речь идет о молодой девушке, страдающей лейкемией, перспективы выздоровления которой были весьма ограниченны. Джейми было отказано местным органом здравоохранения в дальнейшем лечении на том основании, что лечение было болезненным и результаты были плохими; шансы на ее выживание составляли около 1\%. Ее отец настаивал на лечении, исходя из того, что у нее не было других вариантов. С точки зрения ее отца, выбор для его дочери включал две альтернативы: либо пройти лечение с ограниченным шансом на успех, либо смириться с летальным исходом. Мнение органа здравоохранения существенно отличалось. 1 шанс из 100 не означает, что орган здравоохранения играет в игры с жизнью одного ребенка; они означают, что, когда у органа здравоохранения есть 100 детей, которых нужно обслужить, существует вероятность того, что один будет жить и 99 умрут. Для того, чтобы достичь этого результата, управление здравоохранения должно быть готово подвергнуть всех 100 детей болезненной, удручающей программе лечения» [Ham, Pickard 1998].

В случае Джейми Боуэн и ответственные медики, и управление здравоохранения считали, что они не могут оправдать лечение ее в этих обстоятельствах [Ham, Pickard 1998]. Однако суд принял решение в пользу отца. Очевидно, что в такого рода ситуациях решение может быть принято лишь на основе творческой интериоризации проблемной ситуации. Другой пример, демонстрирующий сложность интерпретации публичной услуги, связан с реализацией признака открытости в условиях, когда рациональный подход оказывается недостаточным. Он может быть выражен следующим вопросом: являются ли публичными услуги, производимые государственным сектором для правительства и других государственных органов (например, деятельность Агентства по оборонным закупкам в Великобритании)?

Хотя в логике сервисной модели государства любая его функция рассматривается как публичная услуга, и, следовательно, любая частная функция (т.е., 
составляющая часть основной функции) также должна рассматриваться как публичная услуга, на наш взгляд, имеется важное ограничительное условие она должна быть открытой. Действительно, только при условии, что реализуется такой признак публичной услуги, как открытость, можно гарантировать, что эффект ее будет направлен на достижение единственной цели публичного управления - сохранение и обеспечение жизнедеятельности и развития общества независимо от масштаба этого эффекта. Это подтверждается общеизвестной практикой, когда закрытость деятельности тех или иных государственных органов являлась источником злоупотреблений и коррупции, не имеющих, разумеется, никакого отношения к общественным интересам.

Оба приведенных примера касаются противоречий, которые не могут быть успешно разрешены на основе рациональных подходов и которые можно отнести к противоречиям третьего уровня. Такого рода трудности в большой мере обусловили критику нового государственного менеджмента как парадигмы публичного управления, не говоря уже об административно-бюрократической модели управления. На этой протестной волне появилась череда новых концепций, пытающихся преодолеть противоречия третьего уровня на основании подходов, не сводящихся к рациональной аргументации. К их числу можно отнести аксиологический подход (менеджмент публичных ценностей), когнитивный подход (упор на роль знаний в современном обществе), коммуникативный подход (концепция координационного государства, электронное правительство, сетевые подходы, governance). Несмотря на разную специфику и направленность, они все находятся в рамках так называемой социогуманитарной парадигмы, которая, несмотря на весьма общую формулировку, указывает вместе с тем на определенный вектор развития публичного управления.

В одной из наших работ [Большакова 2019] в качестве современной парадигмы публичного управления предложена концепция сознательного управления (сознательного государства), также органично соединяющая в себе упомянутые концепции, но, по нашему мнению, выгодно отличающаяся от социогуманитарной парадигмы большей степенью операционализированности.

Все они исходят из человекоразмерности общества как объекта управления, т.е. из измеренности его человеческими категориями, понятиями и ценностями и, соответственно, из решения управленческих проблем на основе творческой интериоризации проблемной ситуации с позиций общественных интересов. На основе сказанного, а также с учетом того обстоятельства, что пока не сложился консенсус относительно операционализированной версии социогуманитарной парадигмы, окончательную концептуальную формулу публичной услуги можно представить в форме акта публичного управления, осуществляемого на основе социогуманитарной парадигмы.

Важно сделать еще следующее замечание. Публичная услуга имманентно связана с публичным управлением, и трудности ее концептуализации есть естественное проявление кризиса современного публичного управления на фоне возросшей динамики усложнения общества.

В процессе осуществленной нами концептуализации явственно обозначено движение от формальных, статичных подходов позитивистского толка в сторону придания им содержательного, процессного, диалектического характера - тенденция, не менее явственно проявившаяся и в процессе парадигмального транзита публичного управления.

\section{Список литературы}

Большакова Ю.М. 2019. В поисках парадигмы публичного управления: консцентианетика - сознательное управление. - Власть. Т. 27. № 4. С. 181-186. 
Карловская Е.А. 2009. Государственные услуги в свете концепции экономической социодинамики. - Вестник ТОГУЮ. № 3(14). С. 135-144.

Bolderson H., Mabbett D., Hudson J., Rowe M., Spicker P. 1997. Delivering Social Security: A Cross-National Study: Department of Social Security Research Report No. 59. London: The Stationery Office. xii+279 p.

Ham C., Pickard S. 1998. Tragic Choices in Health Care. London: King's Fund.

Public Administrations and Services of General Interest: What Kind of Europeanisation? (ed. by M. Mangenot). 2005. Maastricht: European Institute of Public Administration.

Spicker P. 2009. The Nature of a Public Service. - International Journal of Public Administration. Vol. 32. Is. 11. P. 970-991.

BOLSHAKOVA Yulia Mikhailovna, Cand.Sci. (Pol.Sci.), Senior Researcher at the Institute of Political Psychology and Applied Political Studies, Pushkin Leningrad State University (10 Petersburgskoye Highway, Pushkin, St. Petersburg, Russia, 196605; academy.prof.com@gmail.com)

\section{CONCEPTUALIZATION OF PUBLIC SERVICES AND PUBLIC ADMINISTRATION}

\footnotetext{
Abstract. The paper attempts to conceptualize public services in the context of public administration. The author shows that a public service is inherently connected with public administration and the difficulties of its conceptualization are naturally associated with the crisis of modern public administration against the background of increased dynamics of the complexity of society.

Overcoming the difficulties of conceptualizing public services is associated with the abandonment of positivist approaches and turning to dialectical ones.

Keywords: public service, conceptualization, public administration, public benefit, public administration crisis
} 